\title{
Fluid Dynamic Characteristics and Flow Distribution Structure Optimization of Axial Piston Pump Considering Cavitation Bubble Evolution
}

\author{
Y. $\operatorname{Pan}^{1 \dagger}$, A. H. Chen ${ }^{1,2}$ and Z. N. Wang ${ }^{1}$ \\ ${ }^{I}$ Country College of Mechanical and Electrical Engineering; Hunan University of Science and Technology, \\ Xiangtan 410083, China \\ ${ }^{2}$ Country Hunan Provincial Key Laboratory of Health Maintenance for Mechanical Equipment, Hunan \\ University of Science and Technology, Xiangtan, China
}

†Corresponding Author Email: ypan2019@126.com

(Received December 2, 2020; accepted April 28, 2021)

\begin{abstract}
An axial piston pump can produce a serious cavitation phenomenon in the high- and low-pressure transition process. Cavitation bubbles expand, compress, rebound and collapse when they enter the high-pressure oil drainage area. This affects the outlet flow ripple as well as the pressure pulsation of the piston pump. However, the effect of the cavitation bubbles is ignored in the current outlet flow ripple model of axial piston pumps. It affects the optimization design of the axial piston pump distribution area structure parameters with the objective of reducing the pressure and flow rate. Therefore, a method of optimizing the fluid dynamic characteristics and the flow distribution area structure parameters of an axial piston pump considering the cavitation bubble evolution is proposed. A single-cavity dynamic model was established to study the bubble evolution as the piston chamber pressure changes. According to the cavitation cloud (group cavitation) characteristics of the axial piston pump, theoretical models of the outlet flow ripple and the pressure pulsation of a piston pump were established considering the cavitation bubble characteristics. The influence of cavitation characteristics on the outlet flow ripples and pressure pulsation of the axial piston pump was analyzed and compared with that without cavitation. Comparison with the experimental results, verified that the outlet flow ripple model becomes more accurate when cavitation bubble characteristics are considered. Based on the multi-agent particle swarm optimization (MAPSO) algorithm, an optimization model of the piston pump outlet flow ripple was established considering the cavitation bubble characteristics. The optimized design parameters for the flow distribution area of the axial piston pump were evaluated. The proposed method can provide theoretical guidance for the design of a low flow ripple axial piston pump.
\end{abstract}

Keywords: Axial piston pump; Cavitation bubble; Flow ripple; MSPOS; Optimization.

\section{INTRODUCTION}

Axial piston pumps, owing to their high efficiency, high power, and high reliability, are widely employed in the automotive, aerospace, and aviation industries. However, the pressure pulsation induced by the outlet flow ripple of the piston pump is the main cause of vibration and noise within the whole hydraulic system, and it is also its main disadvantage. A certain amount of gas is dissolved in the oil during the hydraulic transmission. At every reciprocating movement of the piston, the pump completes the suction and discharge of the oil once. In this process, the piston cavity undergoes a transitions between high and low pressure, which is the main cause of cavitation. When the local pressure of the flow field is lower than the saturated vapor pressure in the working process of the piston pump, the dissolved gas in the oil is separated out and even vaporized (e.g. Wang et al. 2020). Thus, cavitation bubbles enter the high-pressure zone with the oil. Under the action of the local high pressure, these bubbles evolve through expansion, compression, rebound, and collapse processes. This causes internal fluid velocity turbulence and pressure impact, which seriously affect the outlet flow ripple and the pressure pulsation of the piston pump. However, this issue has not yet been addressed in the current flow and pressure model of piston pumps, thus hindering the design of the structure of low-noise piston pumps.

Many studies have focused on establishing an outlet flow ripple model without considering the cavitation characteristics, and this model is typically used to 
optimize the structure of low-noise piston pumps. Ericson and Palmberg (2007) studied the outlet flow ripple and the pressure pulsation at the pump. Their results show that the flow/pressure pulsation is mainly caused by the transition between high and low pressure of the fluid, which is significantly affected by the design of the valve plate structure. Mandal et al. (2008). studied the effect of different grooves on the outlet flow ripple and pressure pulsation of an axial-piston pump based on fluid theory model. Xu et al. (2015, 2016), Ye et al. (2021), and Ma et al. (2010) established the outlet flow ripple model, and verified the correctness of the results through a piston pump flow fluctuation test bench (based on ISO 10767-1-1996) They succeeded in reducing the outlet flow ripple by optimizing the structural parameters of the valve plate.

The above studies show that the progress of research on flow pulsation reduction for piston pumps is mainly based on the flow field effect. Cavitation bubbles are produced during the motion of the piston pump (especially in the transition zone between high and low pressure) The volume change of the cavitation bubble directly affects the fluid instability and increases the outlet flow ripple of the piston pump.

Many researchers have studied the cavitation of piston pumps. Fu et al. (2016) studied the pump flow characteristics under cavitation. Their results show that the generation, development and rupture of cavitation bubbles under transient cavitation conditions have a great influence on the internal fluid flow characteristics. Zhao et al. (2008) established a transient dynamics model considering bubble dissolution and precipitation. They investigated the influence of cavitation and bubble collapse in the fluid system on the fluid characteristics. Their results show that the fluid model is more accurate when considering the characteristics of the bubbles. Liu et al. (2021) studied the cavitation characteristics of a rotating- sleeve flow distribution system. The influence of cavitation on the volumetric efficiency of the piston pump at different speeds and pressures was analyzed. Zhang et al. (2018) studied the pressure pulsation and frequency characteristics of the pump in the cavitation state, and analyzed how the pressure pulsation characteristics change as a consequence of cavitation bubble bursts. Shi et al. (2020) studied the influence of bubble evolution in different cavitation stages on the flow velocity and pressure distribution. They found that cavitation affects fluid flow, especially in the cavitation area, and that the fluid velocity changes greatly, leading to an increased fluid instability.

The effects of cavitation and bubble collapse in the fluid system on the fluid characteristics have been studied. The results show that the fluid model is more accurate considering the characteristics of the bubbles. Ji et al. (2014) investigated the effects of cavitation on pressure fluctuation, and found that the pressure amplitude is related to the volume of the cavitation cloud. Yu et al. (2020) used a numerical method to study the influence of cavitation on pressure fluctuation and fluid noise of hydrofoil craft. Rus et al. (2007) studied the relationship between the cavitation structure and pressure fluctuation of the hydraulic turbine, and they reported how the pressure changes with the cavitation state. Yuan et al. (2015) investigated the influence of gas dynamic characteristics on the oil density and the elasticity model during axial-piston pump cavitation. The flow and pressure characteristics of the axial-piston pump under cavitation were predicted, and the results show that cavitation affects the outlet flow and pressure characteristics of the piston pump. In addition, Tsujimoto (2001), Li et al. (2014), Sloteman et al. (2004), Yamamoto and Tsujimoto (2009), and Lee et al. (2009) analyzed the mechanism of cavitation induced flow instabilities and studied the effects of different structural parameters on the cavitation performance of the pump.

Because of the research on the cavitation characteristics of the piston pump, it is well known that cavitation affects the pump fluid characteristics. However, the influence of cavitation is not considered in the current outlet flow ripple model of the piston pump, leading to inaccurate results for the structural optimization of the piston pump with lowflow pulsation.

To predict more accurately the outlet flow and pressure dynamic characteristics of the axial piston pump, in this study, a fluid model of the axial-piston pump was established considering the dynamic characteristics of cavitation bubbles (expansion, compression, rebound, and collapse). The results show that the calculation of the outlet flow ripple of the piston pump becomes more accurate when considering the dynamic characteristics of cavitation bubbles, as verified by experiments. The outlet flow ripple model established is a nonlinear optimization problem. At present, several models, including particle swarm optimization (PSO) (Liu et al. 2020, Wang et al. 2009) and the genetic algorithm (Liang et al. 2018), are used to optimize the valve plate structure of piston pumps. However, these algorithms tend to produce results that are only locally optimal. Here, a multi-agent particle swarm optimization (MAPSO) algorithm is proposed to optimize the structure of the valve plate. Compared with PSO and the genetic algorithm, MAPSO has a stronger ability to deal with nonlinear optimization, and it can establish whether the obtained optimization result is local or global in nature.

\section{Physical Model of Cavitation Bubbles in AXIAl PISTON PUMP}

A structural schematic diagram of an axial piston pump is shown in Fig. 1. It has nine pistons $(Z=9)$ When the transmission shaft rotates, the piston rotates with the cylinder body around the main shaft, and the same happens in the cylinder body around its own axis. The volume of the piston chamber changes continuously, so as to complete the process of oil suction and discharge. When the pressure is reduced to the saturated vapor pressure, the bubbles dissolved in the oil expand rapidly, and a large amount of gasification occurs locally. This induces the formation of a "cavitation cloud" or "cavitation 

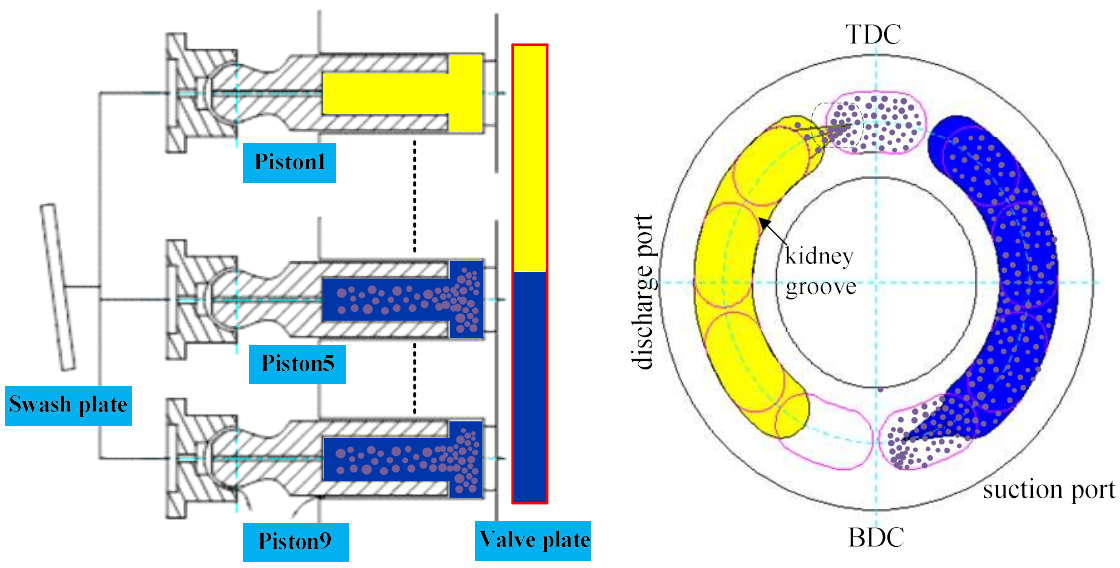

Fig. 1. Schematic diagram of the axial piston pump structure.

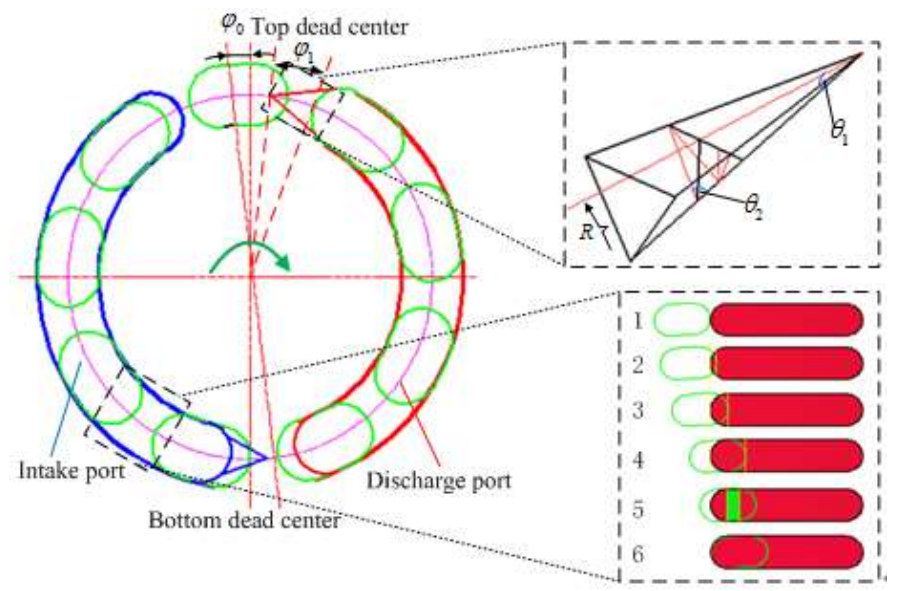

Fig. 2. Schematic diagram of valve plate structure.

group". When a cavitation bubble moves toward a high-pressure area with the piston, it collapses under the external pressure; finally, the bubble disappears in the high-pressure area (Yuan et al.2015).

The collapse of the cavitation group leads to a local pressure impact, which causes surface damage and vibration noise. As the cavitation bubble collapses, its volume space is occupied by the liquid. This leads to an outlet flow transient fluctuation of the piston pump, which aggravates the vibration and noise of the whole hydraulic system. Therefore, the dynamic characteristics of cavitation bubbles (expansion, compression, rebound, and collapse) result in a change in the volume of the liquid discharged from the piston chamber, which in turn affects the outlet flow ripple of the piston pump. To order to reduce cavitation, a damping groove is usually set in the transition area of the valve plate. This groove is mainly composed of a triangular damping groove (including the depth angle $\left(\theta_{1}\right)$ and width angle $\left.\left(\theta_{2}\right)\right)$ and a dislocation angle $\left(\varphi_{0}\right)$, as shown in Fig. 2. Because it is often difficult to determine these parameters in the design of a valve plate, using an optimization algorithm is necessary to minimize the flow ripple.

\section{HYDRODYNAMIC MODELING OF THE PISTON PUMP CONSIDERING CAVITATION BUBBLE CHARACTERISTICS}

\subsection{Mathematical model of bubble dynamics}

To establish the bubble dynamics model, several assumptions are necessary. (1) In the evolution process, the bubble always keeps a spherical shape; (2) The bubble and the liquid flow at the same speed without considering the velocity slip; (3) The water vapor pressure in the bubble is equal to the saturated vapor pressure at the initial ambient liquid temperature; (4) No chemical reaction occurs in the bubble.

According to the Rayleigh-Plesset equation (Fourest et al. 2014), the dynamic equations of bubble expansion, compression, rebound, and collapse in liquid are obtained. In the equation, the effects of viscosity and surface tension are considered.

$\rho\left[R R+\frac{3}{2} R^{2}\right]=p_{v}-p_{\infty}+p_{g 0}\left[\frac{R_{0}}{R}\right]^{3 \gamma}-\frac{2 S}{R}-4 \mu \frac{R}{R}$ 
Where $\rho$ is the density of the liquid, $R$ is the bubble radius, $p_{v}$ is the saturated vapor pressure at the initial liquid temperature, $p_{\infty}$ is the far-field pressure of the liquid, which is the change pressure of piston chamber, $p_{g 0}$ is the gas pressure inside the bubble in the initial state, $R_{0}$ is the initial bubble radius, $\gamma$ is the adiabatic index, which is $1.4 . S$ is the surface tension coefficient, which is $0.072 \mathrm{~N} / \mathrm{m}$, $\mu$ is kinematic viscosity.

Since the bubble contains water vapor and noncondensable gas, the pressure equation of the cavitation collapse is expressed as

$$
p_{R}=p_{v}+p_{g}-\frac{2 S}{R}-4 \mu \frac{R}{R}
$$

Where $p_{g}$ is the gas pressure in the bubble, $p_{g}=p_{g 0}\left(R_{o} / R\right)^{3 k} . k$ is the polytrophic index of gas, which is 1 .

According to Fourest et al.(2014), the cavitation numerical calculation of axial piston pump was studied. The cavitation of the piston pump is a complex cavitation group. Based on the theory of single cavity vibration, the effect of cavitation collapse on the dynamic characteristics of the piston pump was studied using a statistical method. During cavitation bubble collapse, the radiation effect among the various bubble collapse pressures was ignored. Because of the different radii of cavitation bubbles in liquid, the dynamic characteristics of the bubbles are different. In this study, it is assumed that the initial bubble radius follows the Rayleigh distribution(Li et al. 2020)Taking the initial radius of the bubble as a random independent variable; the probability density function is obtained.

$$
f\left(R_{0}\right)= \begin{cases}\frac{\left(R_{0}-R_{\lim }\right)}{\sigma_{R}^{2}} \exp \left[\frac{-\left(R_{0}-R_{\lim }\right)^{2}}{2 \sigma_{R}^{2}}\right] & R_{0} \geq R_{\lim } \\ 0 & R_{0} \leq R_{\lim }\end{cases}
$$

Where $\sigma_{R}=\sqrt{\frac{2}{\pi}}\left(R_{\text {omean }}-R_{\lim }\right), R_{0 \text { mean }}$ is the average of the initial bubble radius, $R_{\lim }$ is the critical bubble size.

According to the fluid simulation results, the gas volume fraction of the piston chamber can be derived. Finally, the number of cavitation bubbles with transient variation can be calculated from the gas volume fraction.

$$
\begin{aligned}
& \alpha=\lambda_{0} \frac{4}{3} \pi R_{\text {omean }}^{3} / V_{\text {piston }} \\
& \lambda_{0}=\frac{3 \alpha V_{\text {piston }}}{4 \pi} R_{0 \text { mean }}^{-3}
\end{aligned}
$$

Where $\alpha$ is the void fraction, $\lambda_{0}$ is the number of cavitation bubbles, $V_{\text {piston }}$ is the volume of piston chamber.

\subsection{Flow and pressure model of single piston considering cavitation bubble evolution characteristics}

In this paper, the $\mathrm{K} 3 \mathrm{~V}$ axial piston pump is used as the main research object. The principle of piston movement is shown in Fig. 3. The displacement, velocity and acceleration of the piston movement are described as.

$$
\begin{aligned}
& s_{i}=s_{0}+R_{\text {piston }} \cos \varphi \tan \beta \\
& v_{i}=-R_{\text {piston }} \omega \sin \varphi \tan \beta \\
& a_{i}=-R_{\text {piston }} \omega^{2} \cos \varphi \tan \beta \\
& \varphi=\phi_{0}+\omega t+2 \pi(n-1) / Z
\end{aligned}
$$

Where $\varphi$ is the position angle of the piston, $\phi_{0}$ is the first piston initial angle, $\beta$ is the angle of the swash plate, $s_{0}$ is the initial displacement at $\varphi=90^{\circ}, R_{\text {piston }}$ is the piston distribution radius, and $\omega$ is the rotational angular velocity of piston pump. According to the piston motion, the volume of the piston chamber can be obtained as:

$V_{f}=V_{0}+\pi d_{p}^{2} R_{\text {piston }} \tan \beta(1+\cos \varphi) / 4$

Where $V_{0}$ is the piston chamber dead volume at the zero-reference line (top dead center) and $d_{p}$ is the diameter of the piston.

The reciprocating motion of the piston causes a volume change of the closed piston chamber. Each piston chamber forms a separate control volume. The oil pressure changes periodically with the rotation of the piston chamber. When cavitation occurs, cavitation bubbles start moving with the piston chamber. According to the mass conservation law, the pressure control equation of the piston chamber, considering the dynamic characteristics of cavitation bubbles, is expressed as.

$\frac{d p}{d \varphi}=-\frac{K_{e}}{\omega V_{f}}\left(\frac{d V_{f}}{d \varphi}-q_{i}-q_{l}-\frac{d V_{g}}{d \varphi}\right)$

Where $K_{e}$ is the fluid bulk modulus, $V_{g}$ is the volume of cavitation bubble, $\frac{d V_{g}}{d \varphi}=\sum_{j=1}^{N} 4 \pi R^{2} \frac{d R}{d \varphi}$; $q_{l}$ is the total leakage, which is calculation reference Yang et al. (2009), the outlet flow through the valve plate can be expressed as:

$q_{i}=C A_{h p} \sqrt{2\left(\left|p_{h}-p\right| / \rho\right.} \cdot \operatorname{sign}\left(p_{h}-p\right)$

$Q=\sum_{i=1}^{n} q_{i}$

Where $\mathrm{C}$ is the flow coefficient, $A_{h p}$ is the effective contact area of the outlet flow of the valve plate discharge port ( $A_{h p}$ can be calculated references 


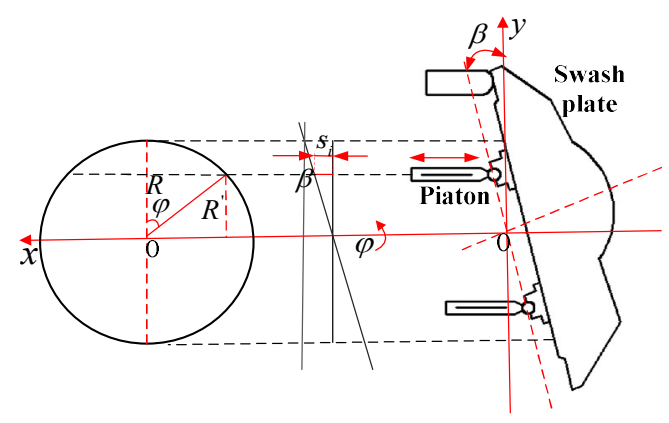

Fig. 3. Schematic diagram of piston movement principle.

Pan et al. (2019)), $p_{h}$ is the load pressure, and $\rho$ is the density of the hydraulic oil.

According to Eqs. (10), (11) and (12), the pressure transient equation in the piston chamber considering the dynamic evolution of cavitation bubble can be written as.

$\frac{d p}{d \varphi}=-\frac{K_{e}}{\omega V_{f}}\left\{\begin{array}{c}-\pi d_{p}^{2} R \tan \beta \sin \varphi+\sum_{j=1}^{N} 4 \pi R^{2} R \\ -C A_{h p} \sqrt{2\left(\left|p_{h}-p\right| / \rho\right.} \cdot \operatorname{sign}\left(p_{h}-p\right) \\ -q_{l}\end{array}\right\}$

\subsection{Multipiston flow and pressure model of piston pump considering bubble evolution characteristics}

In the hydraulic system model, the outlet flow ripple of the hydraulic pump is the main reason for the vibration and noise of the whole hydraulic system. This is mainly due to the piston pump outlet flow pulsation caused by the pressure pulsation in the pipeline. A simplified hydraulic system model is shown in Fig. 4. The pressure fluctuation model of piston pump is established by lumped parameter method with reference Yang et al. ( 2009).

According to the continuity equation and the effect of fluid bulk modulus, the pipeline flow equation can be expressed as (Xu et al. 2016).

$$
\begin{aligned}
& Q_{1}-Q_{2}=\frac{V_{t}}{K_{e}} \frac{d p}{d t} \\
& Q_{2}=C A_{v} \sqrt{2\left(p_{H}-p_{T}\right) / \rho}
\end{aligned}
$$

Eqs. (13) and (16) can be substituted into Eq.(15), the pump outlet pressure can be expressed as

$\frac{V_{t}}{K_{e}} \frac{d p}{d t}+C A_{v} \sqrt{\frac{2\left(p_{H}-p_{T}\right)}{\rho}}=\sum_{i=1}^{9} q_{i}$

According to the bubble dynamic model, single piston flow and pressure model established in Section 3.1 and section 3.2, respectively. They were brought into the multi-piston flow ripple model to

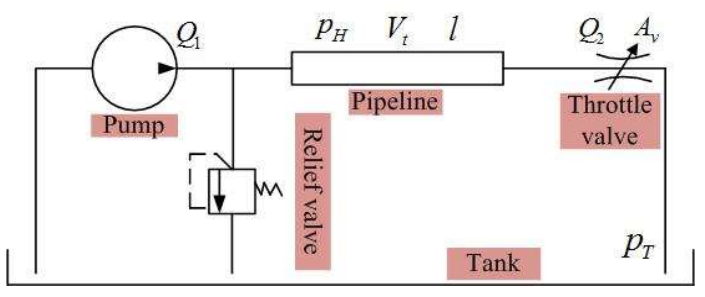

Fig. 4. Hydraulic system simplified model.

obtain the flow and pressure characteristic model of piston pump considering the dynamic evolution of cavitation bubble. The lumped parameter method is used to establish the flow ripple model of piston pump considering cavitation bubble characteristics, which is shown in Fig. 5.

\section{RESUlt ANALYSIS}

\subsection{Dynamic evolution analysis of single bubble}

To describe the evolution process of the cavitation bubble more clearly, the dynamic characteristics of the bubble radius as a function of the pressure of the piston chamber were studied based on the established bubble dynamic model. The structural parameters of the $\mathrm{K} 3 \mathrm{~V}$ axial piston pump are listed in Table 1.

Figure 6 shows the radius variation of a single bubble as a function of the pressure of the piston chamber. when the load pressure of the piston pump is $30 \mathrm{MPa}$.The red curve represents the dynamic evolution of the bubble radius, while the blue curve represents the pressure evolution of the piston chamber. Figure 6 shows that, as the pressure of the piston chamber changes, the bubble undergoes expansion, compression, collapse, and rebound. Furthermore, the dynamic evolution of the bubble mainly occurs in the transition region of the valve plate. The main reason for the cavitation phenomenon is that when low and high pressure contact each other in the piston chamber, the highpressure oil flows to the piston chamber through the valve plate. This produces a large backflow velocity. According to the energy conservation principle of fluid flow, an increase in fluid velocity causes a decrease of local pressure energy and produces strong turbulent kinetic energy, which in turn induces cavitation. For example, the research results of Suo (2018) show that the backflow velocity and turbulent kinetic energy can reach $160 \mathrm{~m} / \mathrm{s}$ and $320 \mathrm{~m}^{2} / \mathrm{s}^{2}$, respectively.

To explain the bubble evolution process more clearly, the local area of Fig. 6 is enlarged. In the zoomed-in inset in Fig. 6, it can be seen that, when the piston chamber rotates from the oil absorption area to the oil discharge area, the bubble radius begins to grow slowly because of the decrease in 


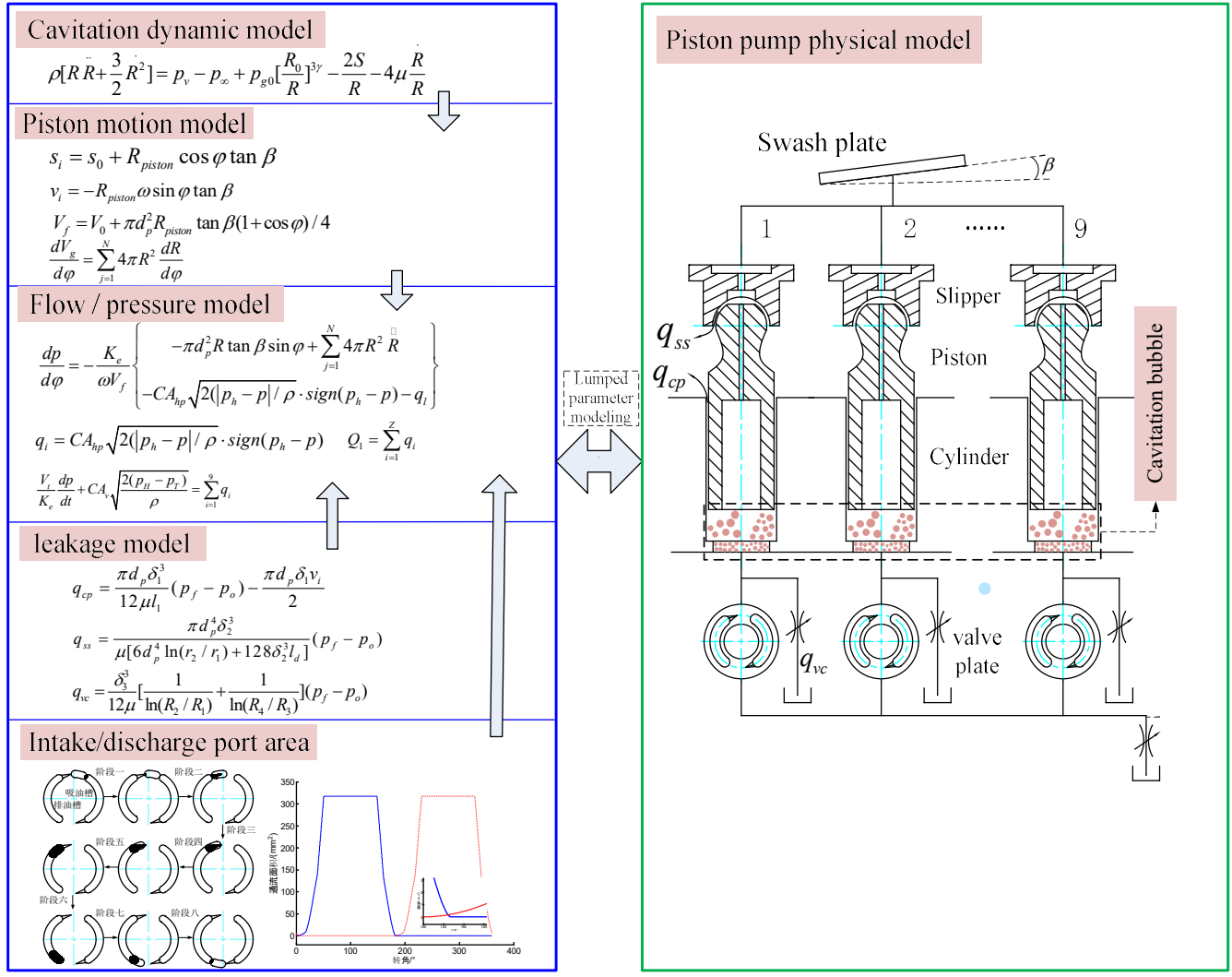

Fig. 5. Flow ripple model of axial piston pump considering cavitation bubble dynamic characteristic.

Table 1 Main structural parameters of axial piston pump.

\begin{tabular}{|c|c|c|c|c|c|}
\hline Symbol & Value & Symbol & Value & Symbol & Value \\
\hline $\mathrm{Z}$ & 9 & $d_{p}$ & $23 \times 10^{-3} \mathrm{~m}$ & $p_{0}$ & $0.5 \mathrm{MPa}$ \\
\hline$R_{0}$ & $6 \times 10^{-5} \mathrm{~m}$ & $\omega$ & $157 \mathrm{rad} / \mathrm{s}$ & $d_{d}$ & $1 \times 10^{-3} \mathrm{~m}$ \\
\hline$V_{0}$ & $9.08 \times 10^{-7} \mathrm{~m}^{3}$ & $C$ & 0.7 & $K_{e}$ & $1.69 \times 10^{9} \mathrm{~Pa}$ \\
\hline$\rho_{0}$ & $870 \mathrm{~kg} / \mathrm{m}^{3}$ & $\beta$ & $0.296 \mathrm{rad}$ & $R_{\text {piston }}$ & $47 \times 10^{-3} \mathrm{~m}$ \\
\hline
\end{tabular}

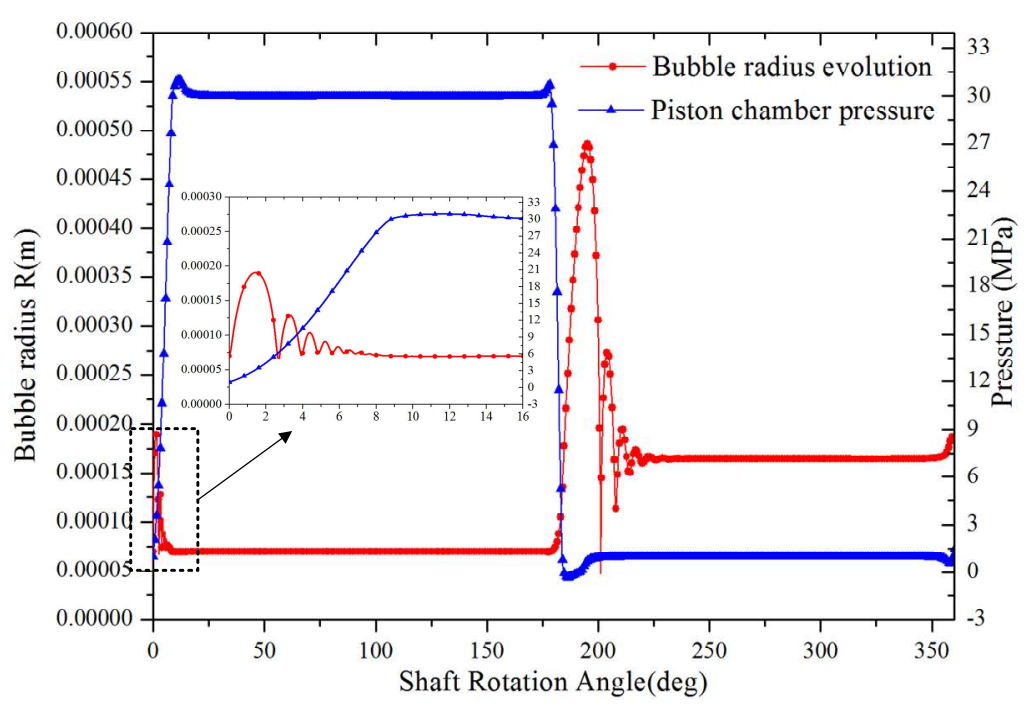

Fig. 6. Evolution characteristics of single bubble radius under 30MPa loading pressure. 


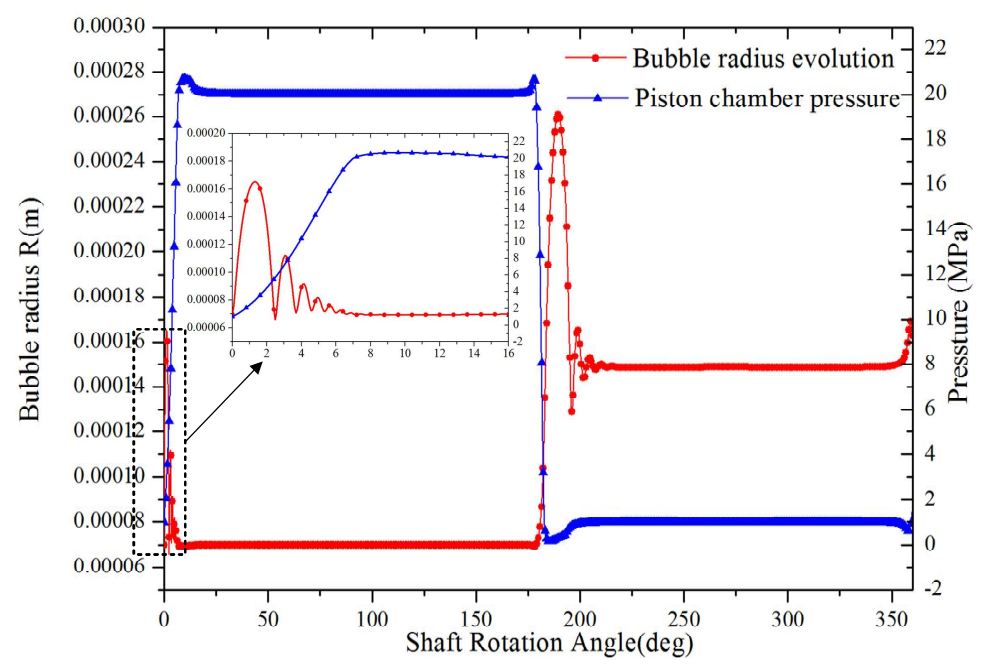

Fig. 7. Evolution characteristics of single bubble radius under 20 MPa loading pressure.

local pressure.As the pressure in the piston chamber increases, the bubble is first compressed, then collapses, and eventually rebounds repeatedly under the action of the gas pressure in the bubble. Finally, the bubbles dissolve in the oil and gradually disappear in the high pressure area. When the piston chamber rotates from the oil drainage area to the oil absorption area, as contact with the oil absorption area is initiated, the pressure of the piston chamber drops below the saturated vapor pressure. This causes the bubble radius to expand rapidly. Upon increasing the pressure, the bubble is first compressed, then collapses, and eventually rebounds repeatedly under the action of the gas pressure in the bubble. Finally, the bubble tends to stabilize at the minimum radius.

Figure 7 shows the variation characteristics of the single-bubble radius as a function of the pressure of the piston chamber, when the load pressure of the piston pump is $20 \mathrm{MPa}$. It can be seen in Fig. 7 that the evolution characteristics of the bubbles are the same as those in Fig. 6.

\subsection{Fluid characteristics of piston pump considering cavitation bubble dynamic characteristics}

To study the influence of cavitation on the fluid characteristics of the piston pump, the cavitation bubble dynamic model was introduced into the fluid dynamic characteristic model of the piston pump. By comparing the flow ripple characteristics with and without considering cavitation, the influence of cavitation bubbles on the fluid dynamic characteristics of the piston pump was analyzed. According to the structural parameters of the $\mathrm{K} 3 \mathrm{~V}$ axial piston pump listed in Table 1, a threedimensional fluid model of the piston pump was established, and its fluid domain grid was divided, as shown in Fig. 8(a)The realizable $\kappa-\varepsilon$ turbulence model and the full gas model were used to calculate the fluid domain. According to the calculation results in Fig. 8(b), the variation characteristics of the total gas volume fraction in the piston chamber is shown in Fig. 8(c). The dynamic variation of the number of cavitation bubbles and the initial radius of the cavitation bubbles obeying the Rayleigh distribution were calculated using Eqs. (4) and (5) The governing equations of the different cavitation bubble radii were then solved. The dynamic evolution of cavitation bubble expansion, compression, rebound, and collapse as a function of the piston chamber pressure was obtained. According to the outlet flow ripple model of the piston pump considering the dynamic evolution characteristics of cavitation bubbles (Fig.5), the outlet flow of the piston pump was calculated. Figs. 9 and 10 show the outlet flow ripple characteristics of the piston pump under different load pressures. The red solid line represents the calculation result considering cavitation, while the black solid line represents the calculation result without considering cavitation. Figs. 9 and 10 show that the outlet flow ripple with cavitation is larger than that without cavitation. This is mainly caused by the expansion and collapse of cavitation bubbles in the piston chamber, which cause the pressure impact of the piston chamber, resulting in the change in the displacement of liquid. Figs. 9(b) and 10(b) show that the increase of the outlet flow ripple of the piston pump mainly occurs in the transition from the oil absorption area to the oil discharge area (the rotation angle of the main shaft is in the range from $0^{\circ}$ to $15^{\circ}$ )In the A area of Figs. 9(b) and 10(b), the outlet flow has a large fluctuation. This is mainly because the piston chamber touches the oil discharge transition zone, and the dynamic evolution of cavitation bubbles (through expansion, compression, collapse, and rebound) causes large fluctuations in the outlet oil volume, which in turn results in oscillations in the outlet flow of the piston pump.

In the B area of Figs. 9(b) and 10(b), the outlet flow with cavitation is larger than that without cavitation. This is mainly because of the pressure impact caused by cavitation bubble collapse as the piston chamber pressure increases. According to Eq. (16), the greater the outlet pressure differences of the piston pump, the greater the outlet flow.To evaluate the correctness of the calculation results considering the 


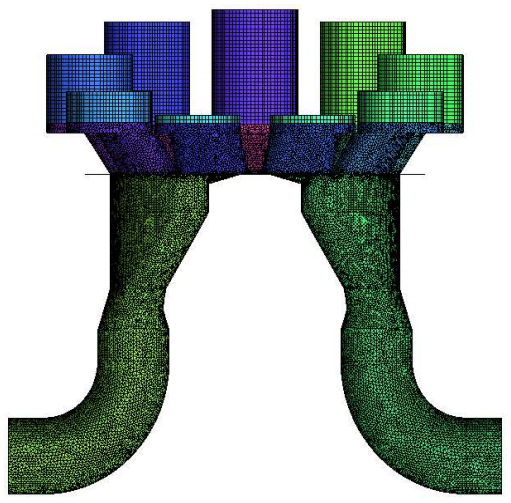

(a)

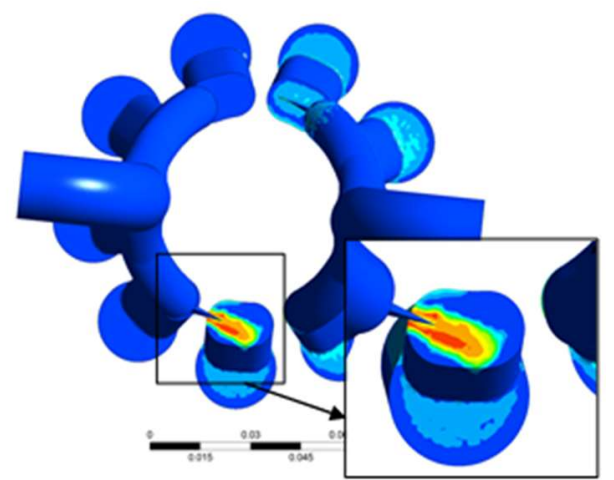

(b)

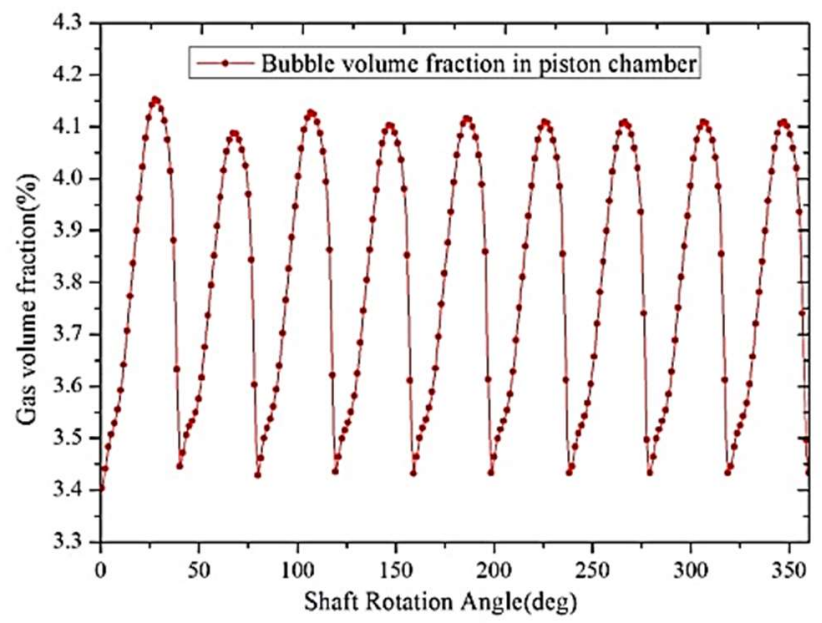

(c)

Fig. 8. Cavitation numerical model analysis of axial piston pump, (a) Three-dimensional fluid model of axial piston pump;(b) Cavitation calculation results of axial piston pump;(c) The gas volume fraction of in piston chamber.

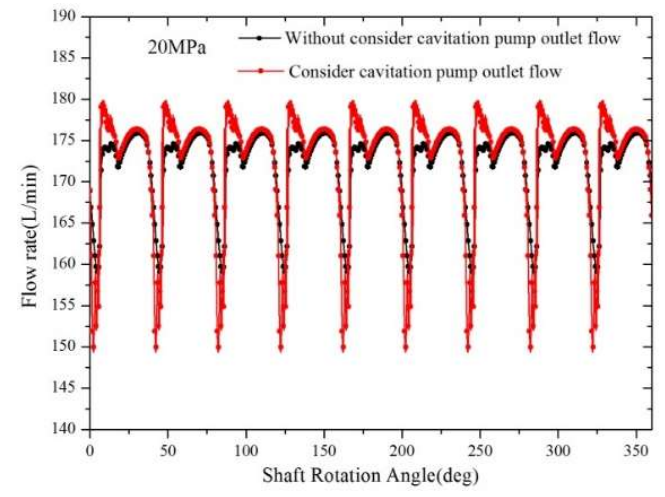

(a)

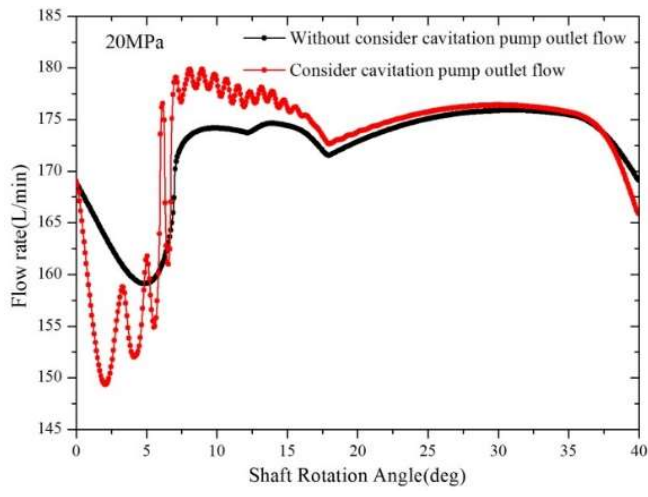

(b)

Fig. 9. Outlet flow ripple characteristics of piston pump with load pressure of 20MPa, (a) The outlet flow of piston pump with rotating shaft for one cycle, (b) 1 / 9 cycle outlet flow ripple.

cavitation bubble flow ripple, these results were compared with the experimental results reported by Ma et al. (2010). Figure 11 of that article reveals that the outlet flow ripple of the piston pump tested in the experiment was larger than that obtained without considering cavitation. In particular, in the B area of Fig. 11 (Ma et al. 2010), the test result is larger than the calculated value without considering cavitation, which is consistent with the calculation of the piston pump outlet flow ripple considering cavitation bubbles in the present study, as shown in Figs. 9(b) and 10(b) The above considerations indicate that the outlet flow ripple model of the piston pump considering the cavitation bubbles is more accurate.

According to the calculation results in Figs. 9 and 10, the outlet flow ripple rates of the piston pump with and without consideration cavitation are presented in Table 2. 


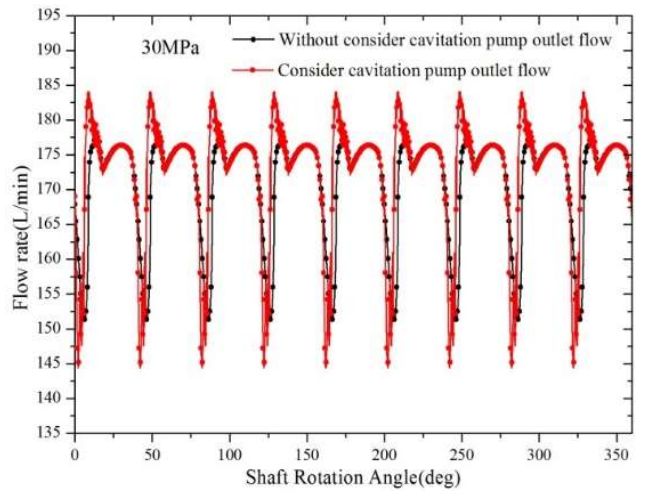

(a)

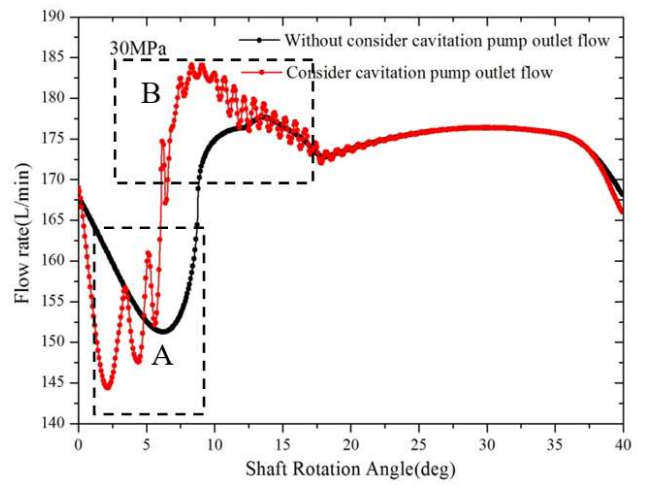

(b)

Fig. 10. Outlet flow ripple characteristics of piston pump with load pressure of 30Mpa, (a) The outlet flow of piston pump with rotating shaft for one cycle, (b) 1/9 cycle outlet flow ripple.

Table 2 Comparison of flow pulsation with and without cavitation.

\begin{tabular}{|c|c|c|c|c|c|c|c|c|}
\hline \multirow[b]{2}{*}{$\begin{array}{l}\text { Flow ripple } \\
\text { comparison }\end{array}$} & \multicolumn{4}{|c|}{ Load pressure $20 \mathrm{MPa}$} & \multicolumn{4}{|c|}{ Load pressure $30 \mathrm{MPa}$} \\
\hline & $\begin{array}{l}\text { Maximum } \\
\text { flow } \\
\text { ( } \mathrm{L} / \mathrm{min})\end{array}$ & $\begin{array}{c}\text { Minimum } \\
\text { flow } \\
\text { (L/min) }\end{array}$ & $\begin{array}{c}\text { Average } \\
\text { flow } \\
\text { (L/min) }\end{array}$ & $\begin{array}{c}\text { Flow } \\
\text { ripple } \\
(\%)\end{array}$ & $\begin{array}{c}\text { Maximum } \\
\text { flow } \\
\text { (L/min) }\end{array}$ & $\begin{array}{c}\text { Minimum } \\
\text { flow } \\
\text { (L/min) }\end{array}$ & $\begin{array}{c}\text { Average } \\
\text { flow } \\
(\mathrm{L} / \mathrm{min})\end{array}$ & $\begin{array}{c}\text { Flow } \\
\text { ripple } \\
(\%)\end{array}$ \\
\hline $\begin{array}{l}\text { Consider } \\
\text { cavitation }\end{array}$ & 179.9 & 149.3 & 172.5 & 17.7 & 180.6 & 143.4 & 171.1 & 21.7 \\
\hline $\begin{array}{l}\text { Without } \\
\text { consider } \\
\text { cavitation }\end{array}$ & 177.7 & 157.5 & 172.6 & 11.7 & 177.7 & 151.3 & 171.2 & 15.4 \\
\hline
\end{tabular}

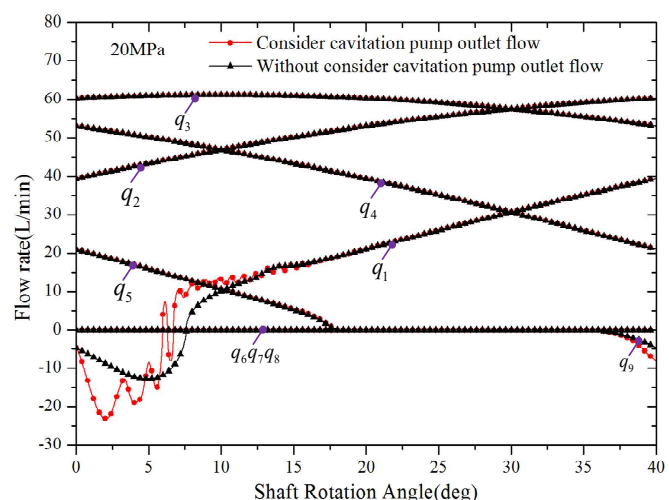

(a)

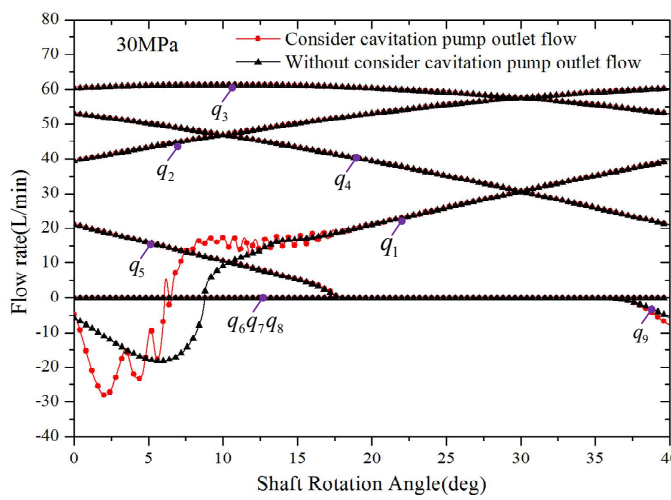

(b)

Fig. 11. Outlet flow characteristics of each piston, (a) Each piston outlet flow with load pressure 20MPa, (b) Each piston outlet flow with load pressure 30MPa.

As it can be seen, when the load pressure is $20 \mathrm{MPa}$, the flow ripple rates with and without considering cavitation are $17.7 \%$ and $11.7 \%$, respectively. At 30 $\mathrm{MPa}$, the flow ripple rates are $21.7 \%$ and $15.4 \%$, respectively. Thus, the flow ripple rate is larger when considering cavitation.

To explain more clearly the influence of the cavitation bubble dynamic evolution on the outlet flow ripple of the piston pump, the outlet flow of each piston during a cycle is shown in Fig. 11. According to Eq. (8), the outlet flow of the piston pump is the sum of the outlet flow of each piston. Figure 11 reveals that the outlet flow of piston $q_{1}$ fluctuates. However, the outlet flow rate of the other pistons is the same as that without considering cavitation. This is mainly because of the dynamic evolution of cavitation bubble expansion, compression, collapse, and rebound during the motion of piston $q_{1}$ from the oil absorption area to the oil discharge area (the rotation angle of the main shaft is in the range from $0^{\circ}$ to $15^{\circ}$ ) The other pistons have no cavitation in the transition zone. This agrees with the conclusions drawn in Sections 4.1 and 4.2.

\subsection{Experimental test analysis}

It is well known that it is difficult to record the outlet flow ripple of the piston pump. Therefore, this paper mainly tests the accuracy of the outlet pressure verification model of the piston pump. The $\mathrm{K} 3 \mathrm{~V}$ piston pump is mainly used in construction 


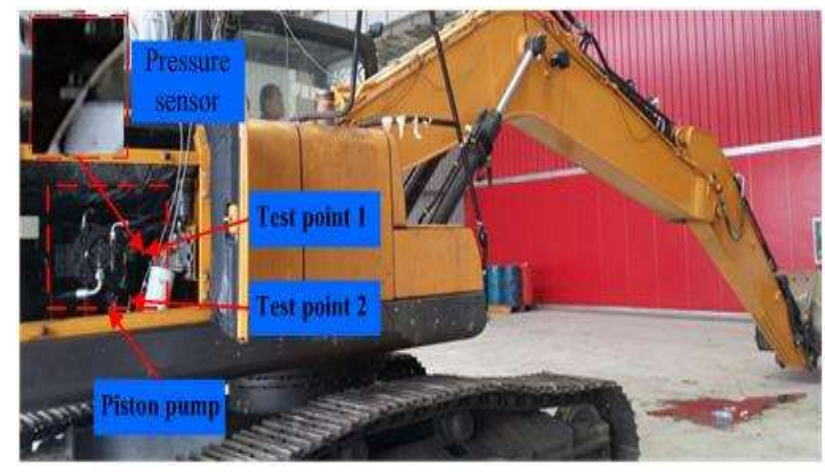

(a)

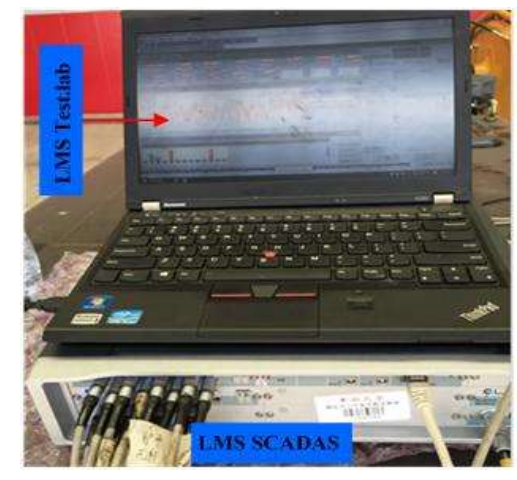

(b)

Fig. 12. Experimental test system of piston pump, (a) Experimental test bench, (b) Data collection.

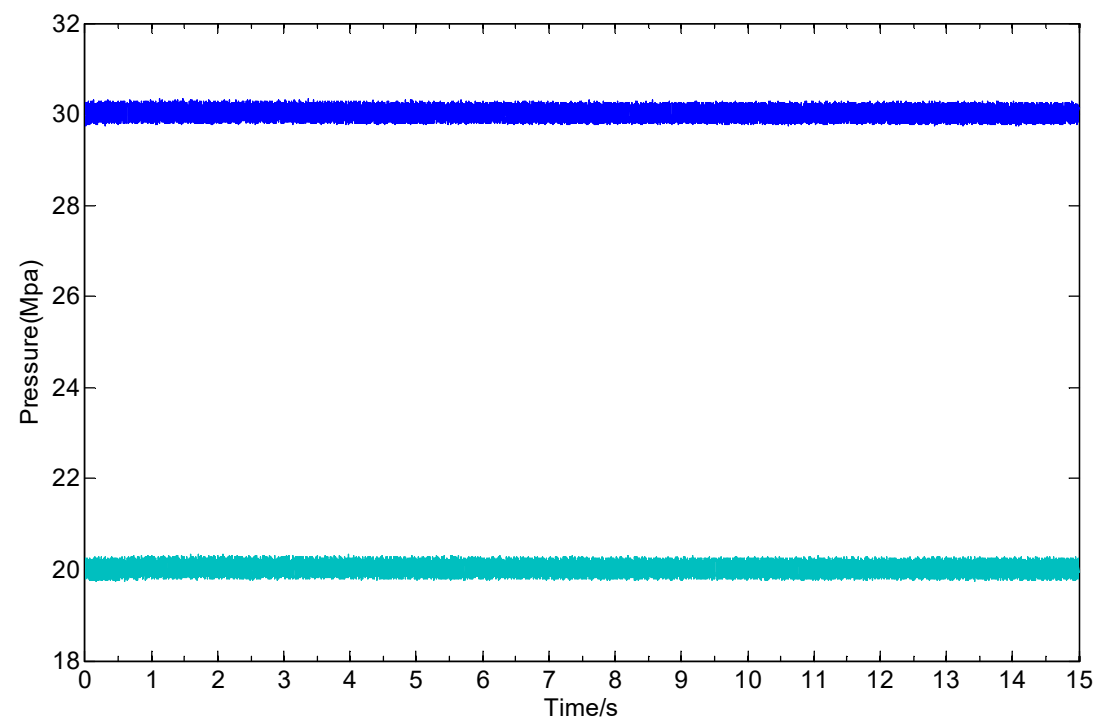

Fig. 13. Experimental test pump outlet pressure data.

machinery (such as excavators) The experimental test setup and system are shown in Fig. 12. The pressure sensor is installed at the outlet of the piston pump. In the test process, the engine speed was $1500 \mathrm{r} / \mathrm{min}$, the sampling frequency was $2048 \mathrm{~Hz}$ and the rated pressure of the pump was $35 \mathrm{MPa}$. To improve the accuracy of the test data, each working condition was tested three times, with a sampling time duration of $15 \mathrm{~s}$. The load pressures were selected as $20 \mathrm{MPa}$ and $30 \mathrm{MPa}$. Figure 13 shows the experimental test results.

The pump speed and outlet pressure in the theoretical model were the same as in the experiment. The pump outlet pressure and theoretical calculation results (with and without cavitation) are shown in Fig. 14, which reveals that the measured pressure is larger than the theoretical calculation result. This is caused by many factors. (1) In this study, the pump outlet pressure on the excavator was mainly tested. The vibration interference and unstable speed of the excavator working conditions have a great influence on the pressure pulsation at the outlet of the piston pump. (2) Because the high pressure and low pressure of the piston chamber change alternately, the torque acting on the swash plate changes.

This causes the swash plate inclination angle to fluctuate. Equation (14) shows that the change of swash plate inclination angle affects the piston chamber pressure. According to the research results of Pan et al. (2019), the pressure fluctuation rate $(1.35 \%)$ calculated by considering swash plate vibration is closer to the test pressure fluctuation rate $(2.4 \%)$ when the load pressure is $20 \mathrm{MPa}$. (3) The experimental results are affected by the pipeline impedance of the excavator. These deviations are acceptable and can provide a favorable value for comparing the outlet pressure of the piston pump with and without cavitation. Comparing the three pressure pulsation curves in Figs. 14(a) and (b), it can be found that the theoretical calculation results when 


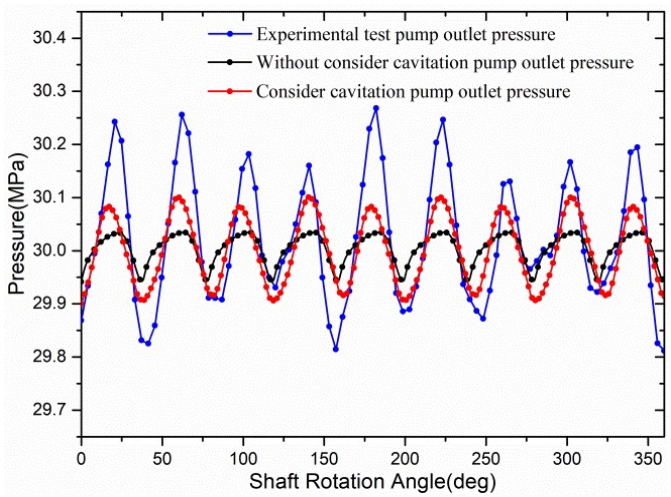

(a)

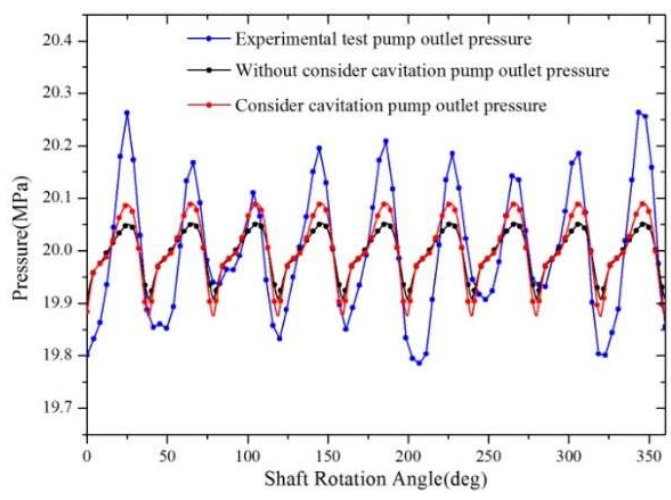

(b)

Fig. 14. Comparison of the pump outlet pressure from the theoretical model and experimental test, (a) Comparison of experimental and theoretical results of $30 \mathrm{MPa}$ load pressure, (b) Comparison of experimental and theoretical results of $20 \mathrm{MPa}$ load pressure.

considering cavitation agree well with the experimental results. Comparing the pressure pulsation with and without cavitation in Fig. 14, reveals that the pressure pulsation calculated using the cavitation model is larger than that without cavitation. The pressure fluctuation calculated by considering cavitation is closer to the experimental results. According to Eq. (16), the greater the pressure fluctuation, the greater the outlet flow ripple of the piston pump. It can thus be inferred that mathematical models of the pump outlet flow ripple are more accurate when considering cavitation. This is the same as the calculation results in Figs. 9 and 10 .

\section{OPTIMIZATION DESIGN ANALYSIS OF VALVE PLATE}

According to Yang et al. (2009), the pump outlet flow ripple is the main performance index for measuring the noise level of a hydraulic system, and is the main source of pressure shock and noise. Therefore, reducing the flow ripple of the piston pump plays an important role in reducing the vibration and noise of the hydraulic system. According to the analysis presented in Section 4.2, the dynamic evolution characteristics of cavitation bubbles have a significant influence on the outlet flow ripple of the piston pump. This affects the valve plate structure design. It is the main structural parameter that causes the outlet flow ripple of the piston pump.

This affects the valve plate design, if the main aim of the design is to minimize the flow ripple amplitude. In this paper, a reference Pan et al. (2019) is provided for calculating the area of the discharge port. According to the description in Section 2.1 (Fig. 2), the main parameters affecting the outlet flow ripple of piston pump include the dislocation angle $\varphi_{0}$, depth angle $\theta_{1}$, and width angle $\theta_{2}$ of the triangular groove. Therefore, by setting $\varphi_{0}, \theta_{1}$, and $\theta_{2}$ as the design optimization variables, the outlet flow ripple can be expressed as:

$$
\left\{\begin{array}{l}
\min J=(\boldsymbol{X}, t) \\
F(\boldsymbol{X}, t)=\max (\mathrm{Q}(\boldsymbol{X}, \mathrm{t}))-\min (\mathrm{Q}(\boldsymbol{X}, \mathrm{t})) \\
\text { s.t. } \boldsymbol{X}=\left[x_{1}, x_{2}, x_{3}, x_{4}\right] \\
x_{1}=\varphi_{0}, x_{2}=\theta_{1}, x_{3}=\theta_{2} \\
0 \leq x_{1} \leq 7 \times \pi / 180 \\
5 \times \pi / 180 \leq x_{2} \leq 18 \times \pi / 180 \\
60 \times \pi / 180 \leq x_{3} \leq 100 \times \pi / 180
\end{array}\right.
$$

Where $F(\boldsymbol{X}, t)$ is the optimal design object function; $\boldsymbol{X}$ represents the optimization design parameters.

The flow pulsation model of a piston pump considering cavitation characteristics is a nonlinear model. In this study, the MAPSO algorithm was used to optimize the structural parameters of the valve plate. MAPSO is a new algorithm that combines PSO and the multiagent algorithm. Each agent particle not only performs the update evolution of the PSO algorithm, but also participates in the competition, cooperation and self-learning with its neighboring particles. Each iteration result interacts with the global optimal objective to cause the optimization result to approach the objective continuously. MAPSO can improve the overall convergence speed and ability to find the optimal results, and it can improve the ability to address complex nonlinear optimization problems.

Take $30 \mathrm{MPa}$ as an example, the optimization iteration process is shown in Fig. 15. The minimum outlet flow ripple rate $(11.84 \%)$ was found when the iteration consists of nine steps, and the optimization results of valve plate structure parameters are listed in Table 3. To verify the accuracy of the optimization results, six groups of valve plate structure parameters were randomly selected, as shown in Table 4.

Table 3 Optimization results of valve plate structure.

\begin{tabular}{|c|c|c|c|}
\hline Parameter & $\varphi_{0}$ & $\theta_{1}$ & $\theta_{2}$ \\
\hline Result & $3.98^{0}$ & $8.55^{0}$ & $70.05^{0}$ \\
\hline
\end{tabular}




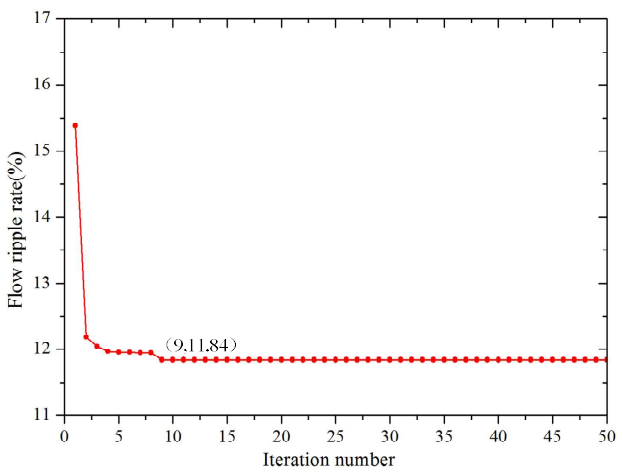

Fig. 15. Iterative process of valve plate structural parameters optimization.

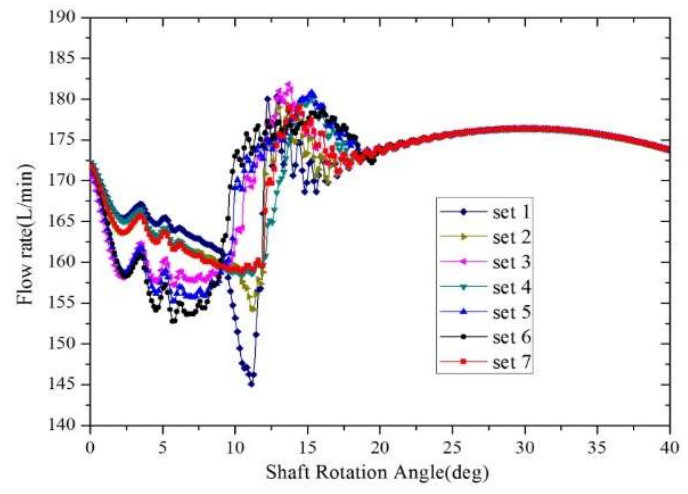

Fig. 16. Comparison of calculation results under different valve plate parameters.

Table 4 Different sets of valve plate structural parameters.

\begin{tabular}{|c|c|c|c|c|}
\hline Set & $\varphi_{0}$ & $\theta_{1}$ & $\theta_{2}$ & Flow ripple rate(\%) \\
\hline 1 & $2^{0}$ & $6.5^{0}$ & $63^{0}$ & 21.02 \\
\hline 2 & $3^{0}$ & $8^{0}$ & $65^{0}$ & 14.77 \\
\hline 3 & $4^{0}$ & $10^{0}$ & $80^{0}$ & 14.42 \\
\hline 4 & $5^{0}$ & $9^{0}$ & $70^{0}$ & 12.68 \\
\hline 5 & $6^{0}$ & $12^{0}$ & $90^{0}$ & 15.02 \\
\hline 6 & $7^{0}$ & $14^{0}$ & $95^{0}$ & 15.20 \\
\hline 7 & $3.98^{0}$ & $8.55^{0}$ & $70.05^{0}$ & 11.84 \\
\hline
\end{tabular}

Table 5 Comparison of calculation results of valve plate parameters under different load pressures.

\begin{tabular}{|c|c|c|c|c|c|c|c|}
\hline Set & $1(\%)$ & $2(\%)$ & $3(\%)$ & $4(\%)$ & $5(\%)$ & $6(\%)$ & $7(\%)$ \\
\hline $10 \mathrm{MPa}$ & 10.36 & 11.65 & 12.08 & 12.54 & 12.94 & 10.65 & 9.5 \\
\hline $20 \mathrm{MPa}$ & 11.39 & 10.23 & 12.99 & 12.50 & 12.53 & 24.33 & 9.89 \\
\hline $30 \mathrm{MPa}$ & 21.02 & 14.77 & 14.42 & 12.68 & 15.02 & 15.20 & 11.84 \\
\hline
\end{tabular}

It can be seen from table 4 that the outlet flow ripple calculated in group 7 is the minimum. It is obtained by optimization in this paper. Figure 16 shows the outlet flow of the piston pump calculated through the combination of different valve plate structure parameters. Here, the red solid line represents the outlet flow ripple curve of the optimized parameters, each of which is the minimum flow ripple rate $(11.84 \%)$

To verify whether the optimized structure parameters of the valve plate can adapt to other external load pressures, different external load pressures were selected, namely $10 \mathrm{MPa}, 20 \mathrm{MPa}$, and $30 \mathrm{MPa}$. Table 5 shows the calculation results of the outlet flow ripple of piston pump under different load pressures. The numbers from one to seven represent different combinations of valve plate structural parameters (Table 4) Table 6 shows that the outlet flow ripple of the pump calculated with seven groups is the smallest, which is the optimized parameter combination in this study. The results show that the optimized valve plate structure parameters are suitable for different pressures.

\section{Conclusion}

Because cavitation bubbles seriously affect the flow and pressure pulsation at the pump outlet, theoretical models of the outlet flow ripple and the pressure pulsation of the piston pump were established considering cavitation bubble characteristics. Based on the MAPOS algorithm, an optimization model of the piston pump outlet flow ripple was established considering cavitation bubble characteristics. A low flow ripple design of an axial piston pump was realized.

The main conclusions are as follows:

1. A bubble dynamics model with the movement of the piston chamber was established. The dynamic characteristics of the bubble evolution with the pressure of the piston chamber were then studied. 
2. Flow and pressure models of a piston pump considering the dynamic evolution characteristics of cavitation bubbles were established. Comparing them with the flow model without cavitation and experimental results verified that the outlet flow ripple model becomes more accurate when cavitation bubble characteristics are considered.

3. An optimization model of axial piston pump outlet flow pulsation based on MAPSO algorithm was proposed. Compared with other structural parameters, the results show that the outlet flow ripple of the optimized structure parameters is the minimum. Furthermore, it was shown that this outlet flow ripple is also the minimum under different load pressure conditions.

\section{ACKNOWLEDGEMENTS}

The project is partially supported by China Postdoctoral Science Foundation funded project (2020M672495), Natural Science Youth Fund of Hunan Province (2020JJ5183, 2020JJ5184), General project of Hunan Provincial Education Department (19C0792).

\section{REFERENCES}

Ericson, L. and J. O. Palmberg (2007) The source admittance method for pumps with complex outlet channels.The tenth international conference on fluid power, SICFP07 279-293.

Fourest, T., J. M. Laurens , E. Deletombe , J. Dupas and M. Arrigoni (2014) Analysis of bubbles dynamics created by Hydrodynamic Ram in confined geometries using the Rayleigh Plesset equation. International Journal of Impact Engineering 66, 73 -74.

Fu, Q., F. Zhang, R. S. Zhu and B. He (2016) A systematic investigation on flow characteristics of impeller passage in a nuclear centrifugal pump under cavitation state. Annals of Nuclear Energy 97,190-197.

Ji, B., X. Luo and Y. Wu (2014) Unsteady cavitation characteristics and alleviation of pressure fluctuations around marine propellers with different skew angles. Journal of Mechanical ence \& Technology 28(4),1339-1348.

Lee, K. H., J. H. Yoo and S. H. Kang (2009) Experiments on cavitation instability of a twobladed turbopump inducer. Journal of Mechanical Science and Technology 23(9), 2350-2356.

Liang, D. D., Y. B. Li , Y. Pan and J. Ma (2018) Multi-objective optimization design and CFD simulation analysis of piston pump. Jisuan Lixue Xuebao/Chinese Journal of Computational Mechanics 35(3), 350-355.

Li, W. Q., Y. Yang and S. H. Jiao (2020) Experimental investigation of s bubble bursting and Its induced jet droplet release. Atomic
Energy Science and Technology, 8, 1-8.

Li, Y., H. Chen, W. Wang and Y Du (2014) Design of inducer with excellent suction performance under multi-operating conditions. Journal of Drainage and Irrigation Machinery Engineering 32 (11), 948-954.

Liu, R., T. Zhang, S. Du, Q. Zhao and H. Zhang (2021) Study on Cavitation Characteristics of Rotating-Sleeve Flow Distribution System. Journal of Applied Fluid Mechanics 14(4),1091-1101.

Liu, Z. Q., J. Y. Cui, H and Q. Dong (2020) Study on Cavitation Resistance Structure of Distribution Plate of High Pressure Axial Piston Pump. Computer Simulation 08,1-6.

Mandal, N. P., R. Saha and D. Sanya (2008) Theoretical simulation of ripples for different leading-side groove volumes on manifolds in fixed-displacement axial-piston pump. Proc IMechE, Part I: J Systems \& Control Engineering, 222(6), 557-570.

Ma, J. E., Y. T. Fang, B. Xu and H. Y. Yang (2010) Optimization of cross angle based on the pumping dynamics model. Journal of Zhejiang Universityence A, 03,181-190.

Pan, Y., Y. B. Li and D. D. Liang (2019) The influence of dynamic swash plate vibration on outlet flow ripple in constant power variabledisplacement piston pump. ARCHIVE Proceedings of the Institution of Mechanical Engineers Part C Journal of Mechanical Engineering Science 233(14), 4914-4933.

Rus, T. and M. 1. Dular (2007) An Investigation of the Relationship Between Acoustic Emission, Vibration, Noise, and Cavitation Structures on a Kaplan Turbine. Journal of Fluids Engineering 129(9), 1112-1122.

Shi, G. T., S. Wang and X. T. Yao (2020) Effect of Cavitation on Flow Characteristic of Multiphase Pump. International Journal Hydroelectric Energy 38(05), 156-159+201.

Sloteman, D. P., D. A. Robertson and L. Margolin (2004) Demonstration of cavitation life extension for suction-stage impellers in high energy pumps. Proceedings of the Twenty-First International Pump Users Symposium 103-115.

Suo, X. Y. (2018) Numerical simulation analysis of cavitation in hydraulic axial piston pump. Yanshan University, China.

Tsujimoto, Y. (2001) Simple rules for cavitation instabilities in turbomachinery .Invited Lecture Proc. 2001 Symposium on Cavitation, 1-16, Osaka University, Japan.

Wang, C., Y. X. Zhang, Z. Y. Yuan and K. Z. Ji (2020) Development and application of the entropy production diagnostic model to the cavitation flow of a pump-turbine in pump mode. Renewable Energy 154, 774-785.

Wang, Z. X. (2009) Study on performance 
Y. Pan et al. / JAFM, Vol. 14, No. 6, pp. 1603-1616, 2021.

optimization method of large flow and high pressure multi-opposed plunger pump. Shandong University of Technology, China.

Xu, B., K. M. Lee., Y. C. Song and H. Y. Yang (2015) A numerical and experimental investigation of parametric effect on flow ripple. ARCHIVE Proceedings of the Institution of Mechanical Engineers Part C Journal of Mechanical Engineering Science 229(16), 2939-2951.

Xu, B., S. G. Ye, J. H. Zhang and C. F. Zhang(2016) Flow ripple reduction of an axial piston pump by a combination of cross-angle and pressure relief grooves: Analysis and optimization. Journal of Mechanical Science \& Technology 30(6), 2531-2545.

Yang, H. Y., J. E. Ma and B. Xu (2009) Research Status of Axial Piston Pump Fluid-borne Noise. Journal of mechanical engineering 45(08), 7179.

Yamamoto, K. and Y. Tsujimoto (2009) A backflow vortex cavitation and its effects on cavitation instabilities .Journal of machinery and systems 2 (1), 40-54.
Ye, S. G., J. H. Zhang, B. Xu, S. Q. Zhu, J. W. Xiang, H. S. Tang (2021) A theoretical dynamic model to study the vibration response characteristics of an axial piston pump. Mechanical Systems and Signal Processing 150, 1-23.

Yu, A., Z. H. Qian, J. J. Ji, Q. H. Tang, H. X. Chen and D. Q. Zhou (2020) Numerical Simulation of Ventilated Cavitation Evolution with an Insight on How Ventilation Influences Pressure Fluctuation and Cavitation Noise.Journal of Applied Fluid Mechanics13 (6),1727-1741.

Yuan, S. H, J. J. Zhou, X. W. Luo and C. B. Jing (2015) Dynamic Evolution and effects of gas phase in cavitation of axial piston pump. Acta Armamentarii 36(3), 559-565.

Zhang, N., B. Gao, Z. Li and Q. F. Jiang (2018) Cavitating flow-induced unsteady pressure pulsations in a low specific speed centrifugal pump. Royal Society Open Science 5(7), 1-16.

Zhao, C. Z., Y. L, H. L. Pan and Y. M. Wei (2008). Effect of cavitation on the transient characteristics of fluid pipeline . Aerospace control and application 34 (03), 61-64. 